\title{
Entre o escrito e o lido, o vivido: o computador como ponte para participação social
}

\author{
Maria Carolina Branco Costa* \\ Ana Lucia Horta Nogueira**
}

Resumo

O artigo pautou-se na necessidade da instituição escolar (re)conhecer o aluno nativo digital, seus modos de operação dos instrumentos técnico-semióticos digitais e o que isso revela sobre seu desenvolvimento psíquico. A pesquisa participante, realizada em uma sala de primeiro ano do Ensino Fundamental de uma escola pública, objetivou analisar as possibilidades do uso do computador como recurso pedagógico no processo de alfabetização, refletindo sobre as repercussões deste instrumento para a atividade docente e discente, enfocando uma situação de prática pedagógica. A realização de uma unidade de leitura sobre um fato social contemporâneo e pesquisa discente colaborativa e orientada, resultou em um texto coletivo. Neste, os alunos puderam se colocar como sujeitos ativos frente aos acontecimentos de seu contexto histórico-cultural, fato que trouxe novos elementos para seu desenvolvimento cultural, ao mobilizar aspectos sociais e recursos tecnológicos. A análise sobre o desenvolvimento cultural infantil a partir da Psicologia Histórico-Cultural permitiu constatar significativa utilização das redes digitais pelas crianças, relacionadas ao lazer e comunicação, observando-se também o distanciamento frente aos fatos sociais de seu tempo. Na medida em que o uso do computador foi pedagogicamente orientado, os alunos experienciaram outros modos de operação, redimensionando suas possibilidades de atuação frente ao universo digital.

Palavras-chave: alfabetização, computador, psicologia histórico-cultural.

Between the written and read, the experienced: the computer as a bridge for a social participation

\begin{abstract}
This paper examined the role of schools in recognizing their students as digital natives susceptible to the influence of technical-semiotical tools on their psychological development. The aims were to analyze possibilities of computer use as a pedagogical tool, reflecting on the repercussions of this instrument for the teaching and student activity, focusing on a situation of pedagogical practice. The data was constructed by a participative and observational study at a public Brazilian primary school. The activity analyzed was a reading unit about a contemporary social fact, based on a collaborative research made by the students, which resulted in a collective text. In this activity, the students were able to place themselves as active subjects of an events of their historical-cultural context, a fact that brought new elements to their cultural development by mobilizing social aspects and technological resources. The analysis of the child cultural development from the Historical-Cultural Psychology allowed to verify significant use of digital networks by children, related to leisure and communication, also observing the distancing from the social facts of their time. Since the use of the computer was pedagogically oriented, the students experienced other modes of operation, redesigning their possibilities of acting in the digital universe.
\end{abstract}

Keywords: literacy, computer, historical-cultural psychology.

\footnotetext{
* Mestra em Educação pela Faculdade de Educação da UNICAMP. Professora de Educação Infantil da rede pública e privada de ensino. E-mail: ma.carolinabc@gmail.com.

** Doutora em Educação pela Universidade Estadual de Campinas e Livre Docência em Psicologia Educacional. Docente da Faculdade de Educação UNICAMP. E-mail: alhorta@ hotmail.com.
} 


\section{Introdução}

As transformações tecnológicas e o uso social das múltiplas linguagens permitiram a identificação de marcas geracionais, presentes nos modos de apropriação e utilização de técnicas, artefatos e linguagens, produzindo nativos e imigrantes digitais. Tais termos, cunhados por Prensky (2001), designam as gerações nascidas antes e depois da virada do milênio, com diferentes graus de domínio das tecnologias digitais. No cenário escolar, estas duas gerações podem ser representadas por professores e alunos.

No contexto atual, o acesso a Tecnologias Digitais da Informação e Comunicação (TDIC) ocorre nas diferentes classes sociais e faixas etárias, que adentram espaços institucionais, dispensam o domínio da escrita, visto que operam com recursos mediadores não verbais, e se adaptam às singularidades do universo privado, sendo altamente personalizáveis. Neste sentido, interessa ao campo educacional investigar quais são os hábitos de acesso e como as crianças em idade escolar operam tais gadgets, especialmente, o computador. Considera-se estes recursos como instrumentos técnicosemióticos, dada sua funcionalidade técnica indissociável da semiótica, e julga-se pertinente acrescentar o termo "digitais", que se reporta à especificidade do computador.

A problemática que sustenta tais discussões é o potencial e os reais modos de uso destes instrumentos que, embora possam permitir acesso a bens culturais, têm sido utilizados, em grande medida, como ferramentas de comunicação, lazer e entretenimento por crianças. Assim, defende-se a necessidade de buscar formas intencionais de mediação pedagógica frente a operação dos recursos digitais para modos de operação mais críticos, mais intencionais e menos arbitrários.

Dado o exposto, indaga-se como as crianças em fase inicial de apropriação da escrita, particularmente, de camadas populares, operam o computador e como os professores podem agregar este instrumento à sua práxis pedagógica, na condição de recurso pedagógico, para orientar os modos de uso e propiciar que os alunos se coloquem como sujeitos ativos frente aos acontecimentos da sociedade que participam. 


\section{Metodologia}

Este artigo integra a pesquisa de mestrado que aborda o processo de alfabetização e desenvolvimento cultural na Era Digital (Oliveira, 2020). O processo de construção dos dados se deu por meio de pesquisa participante, realizada durante oito meses em uma sala de $1^{\circ}$ ano do Ensino Fundamental de uma escola municipal do interior do Estado de São Paulo.

A abordagem metodológica considera o papel participativo da pesquisadora, que se inseriu no campo empírico sob a perspectiva de atuação conjunta; estabelecendo parceria com a professora efetiva da turma investigada; e de atenção às necessidades do meio e dos processos sociais. Segundo Ezpeleta e Rockwell (1989), a pesquisa participante destaca processos que chamam a atenção do pesquisador e são anteriores à sua presença no campo, assim como processos que o pesquisador quer provocar. Nesta pesquisa, a intenção da pesquisadora foi provocar situações pedagógicas que oportunizassem aos alunos outros modos de uso do computador, de modo que as atividades foram planejadas e executadas em parceria com a professora efetiva da turma.

O primeiro semestre letivo - período no qual a pesquisadora inseriu-se em campo durante três meses - destinou-se à coleta de dados documentais e observação dos processos de ensino-aprendizagem. O segundo semestre, dedicou-se à observação participante e realização de atividades, planejadas em conjunto com a professora efetiva, o que permitiu o acesso a aspectos do desenvolvimento cultural e pistas sobre os modos de operação de instrumentos técnico-semióticos digitais pelas crianças investigadas, evidenciando também habilidades de alfabetização, via produções e processos discursivos discentes.

Durante a realização das atividades do segundo semestre, objetivou-se analisar como o computador poderia atuar como recurso pedagógico no processo de alfabetização, observando repercussões para a atividade docente e discente, enfocando uma atividade pedagógica. Para tanto, realizou-se uma unidade de leitura sobre um fato social e pesquisa no computador, o que resultou na produção de um texto coletivo.

A análise se ancorou na abordagem qualitativa (Lüdke \& André, 1986), observando dados como: i) planejamento das atividades em sala de aula e laboratório de informática; ii) processos discursivos fruto das interações durante a realização das 
atividades; iii) produção textual digital coletiva; enfocando os conceitos de mediação, linguagens e desenvolvimento cultural, conforme as contribuições da Psicologia Histórico-Cultural (Vygotsky, 2006), bem como dos estudos de linguagem (Bakhtin, 2003/1979).

\section{Recursos pedagógicos}

A atividade proposta envolveu a pesquisadora, a professora efetiva da turma investigada e 26 alunos de $1^{\circ}$ ano do Ensino Fundamental. O planejamento da atividade pedagógica com uso do computador considerou os seguintes princípios orientadores: a) a intencionalidade pedagógica; b) a reorientação do uso do computador com finalidade didática; c) a ampliação de repertório dos alunos, d) o exercício de habilidades de alfabetização; e) fomento da consciência crítica e participativa dos alunos no âmbito social (princípios inspirados em Sforni, 2015 e adequados ao contexto em questão).

A unidade aqui descrita ocorreu em dois encontros, de cerca de uma hora e meia cada, realizados em duplas, na sala de informática, cujas duplas foram escolhidas randomicamente, e com toda a turma, na sala de aula. Tais encontros integraram outros oito, propostos e desenvolvidos pela pesquisadora, com a presença da professora efetiva da turma, envolvendo outras atividades e direcionados a objetivos mais amplos, concernentes à pesquisa de mestrado da qual este episódio integra.

A unidade de leitura baseou-se na estrutura sugerida por Silva (2003), mobilizando um fato social recente brasileiro (incêndio no Museu Nacional - 2018) e contemplando quatro etapas: a) pré-leitura, b) pós-leitura-constatação; c) reflexão-cotejo; d) intertextualidade; e) transformação. Vislumbrou-se articular a leitura do texto à leitura do mundo, de modo que, a partir da leitura e interpretação do acervo de textos acessados no computador e selecionados coletivamente, os alunos refletiram criticamente sobre a notícia e produziram um texto coletivo para publicação no jornal da escola.

Incialmente foi proposto aos alunos que fizessem o levantamento de textos na sala de informática, através de pesquisa orientada e acompanhada pela pesquisadora. Posteriormente, esses materiais foram organizados e selecionados; conforme adequação de linguagem à faixa etária e apresentação mista de imagem, texto ou vídeo; e cotejados a outros sugeridos pela pesquisadora e professora efetiva, resultando em três materiais 
informativos: a) notícia de jornal digital voltado ao público infanto-juvenil; b) tirinha; c) vídeo informativo, materiais que abarcaram a variedade de recursos semióticos e gêneros textuais encontrados pelas crianças na pesquisa inicial.

Visto que o coletivo docente da escola investigada utilizava orientações e instrumentos da Pedagogia Freinet, tal como o jornal da escola, a pesquisadora sugeriu aos alunos a produção de texto informativo digital coletivo, como forma de sistematizar e avaliar as atividades realizadas. A tabela a seguir detalha os momentos da proposta desenvolvida.

Tabela 1 - Unidade de leitura: incêndio no Museu Nacional

\begin{tabular}{|c|c|c|}
\hline ETAPA & ATIVIDADES & PROVOCAÇÕES \\
\hline \multirow{2}{*}{ 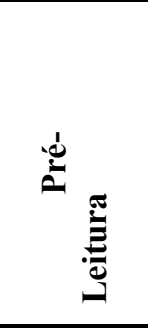 } & $\begin{array}{l}\text { A) Apresentar o título "Museu Nacional, o } \\
\text { mais antigo do país, pega fogo no Rio" e, a } \\
\text { partir dele, realizar questionamentos aos } \\
\text { alunos. }\end{array}$ & $\begin{array}{l}\text { - Sobre o que pode ser esse texto? } \\
\text { - O que pode significar esse título? } \\
\text { - Quais informações você espera encontrar } \\
\text { nesse texto? } \\
\text { - Quais são as características deste gênero } \\
\text { textual? }\end{array}$ \\
\hline & $\begin{array}{l}\text { B) Escrever as respostas na lousa para serem } \\
\text { confirmadas ou transformadas após a leitura. }\end{array}$ & \\
\hline \multirow[b]{2}{*}{$\begin{array}{l}\mathbf{1}^{\mathrm{a}} \\
\text { Leitura }\end{array}$} & \multicolumn{2}{|c|}{ Leitura coletiva de texto com a turma completa (mediada pela pesquisadora e professora) } \\
\hline & $\begin{array}{l}\text { A) Refletir e ponderar sobre essa leitura e } \\
\text { leituras que a antecederam. }\end{array}$ & $\begin{array}{l}\text { - As expectativas criadas a partir do título se } \\
\text { aproximaram ou distanciaram do texto? } \\
\text { - Que sentimentos, sensações e/ou } \\
\text { lembranças você teve ao ler o texto? } \\
\text { - O que você compreendeu do texto? (SILVA, } \\
\text { 2003) }\end{array}$ \\
\hline $2^{\mathrm{a}}$ & \multicolumn{2}{|c|}{ Leitura coletiva em voz alta do texto } \\
\hline \multirow{6}{*}{ 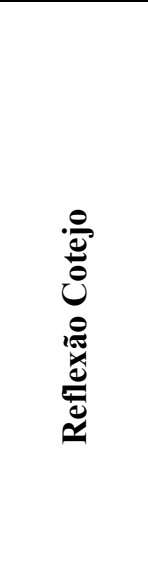 } & \multicolumn{2}{|c|}{3 grupos de até 7 alunos } \\
\hline & $\begin{array}{l}\text { A) Compartilhar as compreensões e } \\
\text { reflexões individuais sobre o enredo do texto. }\end{array}$ & $\begin{array}{l}\text { - Sobre o que é o texto? } \\
\text { - Qual é a notícia que veicula? } \\
\text { - Quais foram as consequências desta } \\
\text { tragédia para o Brasil? }\end{array}$ \\
\hline & $\begin{array}{l}\text { B) Compartilhar e debater percepções sobre } \\
\text { o texto. }\end{array}$ & $\begin{array}{l}\text { - Que elementos nos dizem que esse texto é } \\
\text { uma notícia de jornal? }\end{array}$ \\
\hline & \multicolumn{2}{|c|}{ Turma completa } \\
\hline & \multicolumn{2}{|c|}{ A) Socialização das discussões realizadas nos grupos sobre o enredo e o gênero textual. } \\
\hline & $\begin{array}{l}\text { B) Comentar sobre as características da } \\
\text { notícia de jornal (texto informativo). }\end{array}$ & $\begin{array}{lcr}- & \text { Texto } & \text { jornalístico: } \\
- & \text { Linguagem } & \text { formal; } \\
- & \text { Relato } & \text { imparcial dos } \\
\text { - } & \text { Aborda fatos históricos em tempo real. } \\
\end{array}$ \\
\hline
\end{tabular}




\begin{tabular}{|c|c|c|}
\hline & \multicolumn{2}{|c|}{ Duplas ou grupos de três alunos } \\
\hline & $\begin{array}{l}\text { A) Apresentar a tirinha e suas características; } \\
\text { B) Debate em grupo sobre as interpretações } \\
\text { a partir da tirinha. }\end{array}$ & $\begin{array}{l}\text { Características: } \\
\text { - } \quad \text { Linguagem } \\
\text { - Narrativa intimista e coloquial; } \\
\text { - } \quad \text { Um ou poucos personagens; } \\
\text { - } \quad \text { Espaço e tempo limitados; } \\
\text { - Aborda fatos do cotidiano; } \\
\text { - A qual a ideia vinculada na tirinha? } \\
\text { - Qual a preocupação mostrada pelo } \\
\text { personagem } \\
\text { - Há humor nesta tirinha? Ou é crítico- } \\
\text { reflexiva? } \\
\text { - De que forma se pode relacionar a tirinha e } \\
\text { a notícia do Jornal Joca? }\end{array}$ \\
\hline & \multicolumn{2}{|c|}{ Turma completa organizada em roda de conversa } \\
\hline 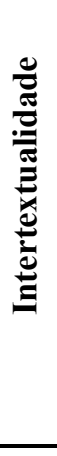 & $\begin{array}{l}\text { A) Questionar os alunos sobre o papel e a } \\
\text { importância dos museus como fonte de } \\
\text { acesso a história e ciência e como espaço } \\
\text { cultural. } \\
\text { B) Debater a existência de museus na cidade } \\
\text { e no país (complementar o diálogo com } \\
\text { informações do texto: "Peritos já sabem onde } \\
\text { começou o fogo no Museu Nacional; } \\
\text { hipótese de incêndio criminoso não é } \\
\text { descartada"). }\end{array}$ & $\begin{array}{l}\text { - Vocês já foram a um museu? } \\
\text { - O } \\
\text { - Por que é fácil acreditar nesse tipo de } \\
\text { notícia? } \\
\text { - Como o incêndio poderia ter sido evitado? } \\
\text { - Quais podem ser os interesses de o Poder } \\
\text { Público não investir na manutenção dos } \\
\text { museus? }\end{array}$ \\
\hline 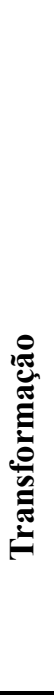 & $\begin{array}{l}\text { Proposta aos alunos: Imaginar que são } \\
\text { jornalistas e escrevem para um jornal, cuja } \\
\text { missão é informar a população estudantil } \\
\text { sobre os acontecimentos do Brasil. Para } \\
\text { tanto: } \\
\text { A) Cada grupo (mediado pela pesquisadora } \\
\text { ou professora) deve escrever uma notícia } \\
\text { respondendo a uma das questões propostas } \\
\text { (referentes ao início, meio e fim da notícia); } \\
\text { B) Ao final, a partir das elaborações, a turma } \\
\text { irá redigir um texto único, para posterior } \\
\text { publicação no Jornal da Escola. } \\
\text { Finalizar com a exposição de vídeos e } \\
\text { imagens de antes e depois do incêndio. }\end{array}$ & $\begin{array}{l}\text { Questões norteadoras para cada grupo: } \\
\text { 1) O que aconteceu? (informar o que e onde } \\
\text { ocorreu o fato); } \\
\text { 2) Como aconteceu? (informar como e } \\
\text { porque ocorreu o fato); } \\
\text { 3) Desdobramentos (informar o que ocorreu } \\
\text { depois deste fato e implicações para a história } \\
\text { do Brasil). } \\
\text { - Socialização; } \\
\text { - Revisão: atende às características do gênero } \\
\text { jornalístico comentadas anteriormente? } \\
\text { (linguagem, forma e conteúdo); } \\
\text { - Elaboração coletiva de um texto } \\
\text { jornalístico. }\end{array}$ \\
\hline
\end{tabular}

Fonte: elaboração da autora.

Em todo o processo, a atividade das crianças foi mediada pela pesquisadora e pelo material semiótico presente nos materiais escritos, imagéticos e audiovisuais veiculados pelo computador. Durante a realização da atividade de pesquisa digital, buscou-se observar como os alunos operavam o computador e como o utilizavam como fonte de 
informação, ao mesmo tempo em que eram orientados para o uso deste instrumento digital.

Os alunos demonstraram dificuldade e dúvidas básicas para a operação do computador, por exemplo, como ligar e aumentar o volume e qual botão do mouse deveriam utilizar, demonstrando um uso incipiente do instrumento, cuja aprendizagem baseava-se em acertos e erros. Comentaram estar mais habituados ao uso dos smartphones (próprios e de familiares, cuja operação, segundo as descrições, alinhava-se ao modo intuitivo de uso).

\section{Análises}

A elaboração da atividade e a dinâmica de seu desenvolvimento nesta sala de aula podem ser analisadas segundo uma abordagem qualitativa (Lüdke \& André, 1986), considerando "os cinco princípios orientadores da ação docente" descritos por Sforni (2015, p. 381) que nortearam o planejamento da atividade. Segundo a autora, os princípios, que fundamentam os procedimentos didáticos que podem favorecer a aprendizagem e o desenvolvimento dos estudantes, são: 1. Princípio do ensino que desenvolve; 2. Princípio do caráter ativo da aprendizagem; 3. Princípio do caráter consciente; 4. Princípio da unidade entre o plano material (ou materializado) e o verbal; 5. Princípio da ação mediada pelo conceito. Nas análises apresentadas a seguir, serão ressaltados os princípios 1,2 e 4 .

O Princípio do ensino que desenvolve $\left(1^{\circ}\right)$ efetivou-se sob a ação da pesquisadora de organização de situações pedagógicas desafiadoras, do ponto de vista do desenvolvimento psíquico, que visaram provocar e atuar na zona de desenvolvimento proximal do alunado, uma vez que, coletivamente, questões de alfabetização foram abordadas, sob a mediação semiótica (signo-palavra) e interpessoal (exercida através dos pares e da professora). A ação da pesquisadora foi intencional, planejada e mediada, oferecendo, para além do caráter semiótico e instrumental, outros modos de participação do alunado. Neste sentido, este princípio foi contemplado à medida que a ação aleatória de operação do computador foi direcionada a uma ação orientada, pela pesquisadora e professora. 
O Princípio do caráter ativo da aprendizagem $\left(2^{\circ}\right)$ remeteu aos modos de participação individuais e coletivos dos estudantes. A participação ativa e constante dos alunos permitiu à pesquisadora e à professora efetiva reorganizarem as ações pedagógicas, observando os conceitos que os alunos já haviam ou não se apropriado.

Observou-se o Princípio da unidade entre o plano material (neste caso, o computador e os materiais disponibilizados pela pesquisadora durante a unidade de leitura) e o plano verbal ( $4^{\circ}$ ) (linguagem oral e escrita), presente durante todo o processo, como elemento central, enquanto mediadora das ações do alunado, viabilizando a apropriação de conceitos e a organização das ações e do pensamento.

As situações vividas em sala de aula permitiram aos alunos a possibilidade de outros modos de operar e o acesso a linguagens variadas (sonora, visual e audiovisual). Para Rojo (2016, p. 21), as mídias digitais: "facilitam a modificação e recombinação de conteúdos oriundos de quaisquer mídias", o que ocorreu nesta atividade, que combinou as imagens resultantes de fotografias das produções artísticas dos alunos e o texto digital.

Com relação à presença da linguagem digital, compreende-se que esta permitiu reconfigurar as modalidades de linguagem e mídias digitais, facilitando "a modificação e recombinação de conteúdos oriundos de quaisquer mídias" (Rojo, 2016, p. 21), o que ocorreu por meio da recombinação das imagens das produções artísticas dos alunos e de texto digital.

A análise da atividade dos alunos ainda remete a uma das aprendizagens requeridas pela Era Digital, que se trata da capacidade de lidar com o funcionamento hipertextual. Importante ressaltar que se observou uma diferença entre os alunos menos e mais avançados no processo de apropriação da escrita. Mesmo cientes dos objetivos da atividade, os alunos em processo inicial de alfabetização acessaram vários conteúdos divergentes, o que não ocorreu com aqueles alunos mais avançados na alfabetização. Enquanto o primeiro grupo pareceu se guiar por signos não verbais (como imagens, propagandas, emoticons e outros recursos visuais), o segundo grupo manteve-se mais atentos às palavras na condução de sua pesquisa, acessando os conteúdos esperados, segundo os objetivos previamente traçados.

Esta observação se faz pertinente visto que um dos objetivos da pesquisadora nesta atividade era verificar como os alunos operavam o computador em uma situação previamente direcionada, a qual previa pesquisar imagens, notícias, vídeos e outros 
conteúdos relacionados ao Incêndio no Museu Nacional, no Rio de Janeiro na Internet, visando levantar informações para melhor compreensão deste fato social.

A partir deste apontamento, considera-se que o domínio da linguagem escrita revela um mecanismo de poder e controle de sentidos, conforme afirma Gnerre (1994), uma vez que os alunos em processo inicial de alfabetização direcionaram-se expressivamente pelas imagens, cores e sons - recursos semióticos não verbais, em contraponto aos alunos mais avançados neste processo, cuja operação foi direcionada por palavras. Esta observação permite concluir que o domínio do código linguístico alterou os conteúdos de acesso e o direcionamento da pesquisa. Para Lemke (1998, s/p apud Rojo, 2016, p. 21): "o hipertexto permite que saltemos de um texto a outro e de um ponto de saída a múltiplos portos de ancoragem, por meio da inserção de lincagens permitidas em ambiente virtual". Este fenômeno é apropriado e passa a ser um modo de organização psíquica, mobilizando todas as funções psicológicas superiores.

Após a realização de pesquisa no laboratório de informática para levantamento de informações sobre o Museu Nacional, a pesquisadora organizou selecionou e apresentou os materiais à classe. Os materiais apresentados foram: notícia de jornal digital voltado ao público infanto-juvenil; tirinha e vídeo informativo. Com o auxílio da pesquisadora e da professora efetiva, a turma escreveu um texto coletivo, utilizando, para isto, o computador em sala de aula. A professora foi a escriba e utilizou o programa Microsoft Word, projetando a tela do computador na lousa, de forma que os alunos podiam acompanhar o texto à medida em que estava sendo escrito:

\begin{tabular}{|c|}
\hline MUSEU PEGOU FOGO NO RIO DE JANEIRO \\
NO MÊS DE SETEMBRO O MUSEU NACIONAL, NO RIO DE JANEIRO, PEGOU FOGO. \\
A CAUSA DESSE INCÊNDIO AINDA ESTÁ SENDO INVESTIGADA PELA POLÍCIA. \\
DENTRO DO MUSEU HAVIA QUADROS, OSSOS DOS HUMANOS MAIS ANTIGOS DA \\
AMÉRICA LATINA, HAVIA TAMBÉM OSSOS DE DINOSSAUROS. \\
O MUSEU ERA MUITO IMPORTANTE PARA NOSSO PAÍS PORQUE NELE HAVIA \\
MUITAS COISAS QUE NÃO EXSITEM MAIS. ERA IMPORTANTE TAMBÉM PORQUE \\
PODÍAMOS CONHECER NOSSO PASSADO. \\
QUANDO O MUSEU PEGOU FOGO E OS BOMBEIROS CHEGARAM NÃO TINHA \\
ÁGUA PARA ELES CONTROLAREM O FOGO POIS O MUSEU ERA MUITO ANTIGO E ESTAVA \\
SEM MANUTENÇÃO, SEM DINHEIRO PARA SEU CUIDADO.
\end{tabular}


AQUI NA SALA DE AULA DO $1^{\circ}$ ANO B, TURMA DAS BORBOLETAS NÓS ESTAMOS INVENTANDO COISAS QUE AINDA NÃO EXISTEM E QUE UM DIA PODEM ESTAR NO MUSEU.

ELES PODERIAM TER TIRADO FOTOS, OU DESENHADO NO PAPEL, OU ESCRITO, TER FEITO VÍDEOS.

AUTORES: TURMA DAS BORBOLETAS - 07 de dezembro de 2018.

Durante a elaboração do texto, a professora efetiva e a pesquisadora fizeram perguntas para auxiliar no processo de escrita, tais como: "O que aconteceu? Onde? Como? O que eles poderiam ter feito para preservar as obras?". A atividade permitiu a organização e síntese de ideias, a ampliação de vocabulário e, durante elaboração do texto, a professora ainda fez algumas intervenções quanto a aspectos ortográficos, por exemplo: "- A palavra: "incêndio" se escreve com S ou com C? E "polícia"...?".

Nesta situação, o gênero textual "notícia de jornal" (texto informativo) foi hibridizado à esfera digital, analisado frente a outros gêneros (por exemplo, tirinha e vídeo informativo). Pode-se brevemente retomar aqui a discussão sobre flexibilização, hibridismo e intercalação dos gêneros textuais propostas por Rojo (2016):

Portanto, exercer uma prática de linguagem situada significa, entre outras coisas, selecionar e operar nos parâmetros (flexíveis) de gêneros discursivos. Mas o gênero em que se dá o enunciado não é, como querem alguns, apenas um formato. Ele define formas de composição do enunciado e seu estilo. (ROJO, 2016, p. 28).

Ao possibilitar a apropriação de discursos sociais mais amplos e mais estáveis na cultura, os gêneros textuais medeiam de diferentes formas as funções psicológicas superiores. Deste ponto de vista, abordar a variedade de tipologias textuais é fundamental para a apropriação de diferentes formas de discursos, conforme defende Dolz e Schnewly (2004).

A perspectiva dialógica da teoria do Círculo de Bakhtin (Bakhtin, 2003/1979), neste contexto, continua relevante, à medida que permite ampliar e abranger novas formas de linguagem e suportes. Conforme Tanzi Neto et al (2016), a teoria dos gêneros permite relacionar inúmeras possibilidades de enunciados/enunciações/textos/discursos/designs.

Considerando as novas e inúmeras práticas de linguagem emergentes nas mídias contemporâneas e nos recursos tecnológicos disponíveis e em desenvolvimento, poderíamos pensar que a concepção de gênero apresentada neste breve recorte não daria conta das linguagens da alta modernidade. De fato, a concepção de gênero do discurso não teria a obrigatoriedade de abranger 
todas as formas de comunicação - como um conceito onipresente, onipotente e autosuficiente - embora anuncie o caráter de inacabamento que deixa a concepção aberta e flexível (Tanzi Neto et al, 2016, p. 139-140).

Neste sentido, pontua-se que as possibilidades oferecidas pelos instrumentos digitais transcendem o acesso à informação e a operação da máquina, mas possibilita aprendizagens que atuam no desenvolvimento cultural, abrangendo o desenvolvimento psíquico, e na participação social dos sujeitos, uma vez que as funções psicológicas superiores foram anteriormente funções sociais, conforme Vigotski (2006, p. 150, tradução das autoras): "Por trás de todas as funções superiores e suas relações se encontram geneticamente as relações sociais, as autênticas relações humanas".

\section{Resultados e Discussão}

Inicialmente, observou-se que os alunos operavam o computador de forma intuitiva, através de estratégias de tentativa e erro, visto que não souberam responder o motivo de tais procedimentos ou antecipá-los quando questionados. A partir das diversas estratégias didáticas propostas (como a pesquisa direcionada, a unidade de leitura e a produção coletiva de texto informativo), foi possível unir aspectos de ensinoaprendizagem, desenvolvimento cognitivo e cultural, mobilizando leitura, escrita e criatividade, funções psicológicas superiores (como atenção, concentração, memória, raciocínio). As orientações técnicas para o uso adequado do computador possibilitaram transformar a ação intuitiva em elaborações cognitivas e participação social mais ampliadas, culminando na reorientação do uso deste instrumento digital.

Além disto, as diversas formas de mediação durante as atividades, entre elas as indagações da pesquisadora, permitiram a reconfiguração do olhar dos alunos para o fato social e para a escrita, despertando-os para a ocupação de uma postura ativa, reflexiva e crítica, que, finalmente, expressou-se sinteticamente em texto coletivo direcionado ao jornal da escola, com função informativa.

Sob a óptica do desenvolvimento, constatou-se que mencionar as expressões do universo digital não significa ter se apropriado ou ter domínio delas, o que foi verificado ao questionar os alunos sobre o significado destas; ao mesmo tempo que utilizar o instrumento não significa dominá-lo ou operá-lo com propriedade. 


\title{
Considerações Finais
}

Considera-se que a unidade de leitura atingiu os objetivos propostos, na medida em que mobilizou os diferentes agentes escolares e repercutiu na interação entre eles, além de inserir o computador como recurso pedagógico e provocar o desenvolvimento cultural. As observações realizadas durante a intervenção pedagógica nesta sala de aula levam a problematizar as implicações e possiblidades do uso dos recursos digitais no contexto escolar, como já indicado por Jobim e Souza e Gamba Jr (2002).

\begin{abstract}
A produção do conhecimento hoje não dispensa a nossa capacidade de dialogar com os aparatos tecnológicos, incentivando as pessoas a construírem, com eles, novas possibilidades de usos, submetendo as máquinas ao nosso poder e desejo de inventar outros jogos ainda não revelados na prática. Trata-se, portanto, de criarmos, por meio da educação, modos de confronto com a experiência tecnológica, colocando tanto educadores como educandos na posição de se sentirem responsáveis por inventar outras estratégias de interação na produção de conhecimento (JOBIM E SOUZA; GAMBA JR., 2002, p. 113).
\end{abstract}

Observou-se que a atividade proposta redimensionou a utilização que os alunos faziam do computador, enquanto espaço digital para lazer e comunicação. Evidenciou-se as múltiplas possibilidades de uso do instrumento, o que os aproximou do universo da informação e comunicação que este congrega, permitindo que os alunos atuassem com propósitos mais amplos do que puramente entretenimento, assim como mais atentos às propagandas e aos apelos do marketing ao consumo.

A unidade de leitura permitiu a interlocução entre gêneros textuais, estratégias didáticas mediadas pela pesquisadora, professora e recursos semióticos atuante na zona de desenvolvimento proximal. A atividade permitiu a aproximação das linguagens de nativos e imigrantes digitais, sob uma perspectiva ativa, crítica e reflexiva, além de permitir que os alunos se recolocassem no cenário social, atuando como sujeitos produtores de cultura. Além disto, a interação entre os discentes, professora efetiva e a pesquisadora foi sintetizada em registro da linguagem verbal, por meio da escrita realizada no computador e simultaneamente projetada na lousa.

Considera-se ainda que os princípios norteadores do ensino (SFORNI, 2015) podem ser ampliados pelos professores, com vistas a criação de outros modos de utilizar o computador como recurso pedagógico, sem perder de vista a dimensão das relações de ensino, do desenvolvimento cultural e da participação social. 


\section{Referências}

BAKHTIN, M. Marxismo e filosofia da linguagem. São Paulo: Editora Hucitec, 2003/1979.

EZPELETA, J.; ROCKWELL, E. Pesquisa participante. São Paulo: Cortez Editora, 1989.

GNERRE, M. Linguagem, Escrita e Poder. São Paulo: Martins Fontes, 1994.

JOBIM E SOUZA, S.; GAMBA JR., N. Novos suportes, antigos temores: tecnologia e confronto de gerações nas práticas de leitura e escrita. Revista Brasileira de Educação. Rio de Janeiro: 21, 104-114, dez. 2002.

LÜDKE, M.; ANDRÉ, M. E. D. A. Pesquisa em educação: abordagens qualitativas. São Paulo: EPU, 1986.

OLIVEIRA, M. C. B. C. A. de. Modos de participação de crianças em práticas digitais no $1^{\circ}$ ano do ensino fundamental. 2020. 164 f. Dissertação. Programa de Pós-Graduação em Educação. Universidade Estadual de Campinas, UNICAMP, Campinas, 2020.

PRENSKY, Marc. Digital natives, digital immigrants. In. On the Horizon, v. 5, n. 9, p. 16, 2001.

ROJO, R.; ALMEIDA, E. de M. (Orgs.). Multiletramentos na escola. São Paulo: Parábola Editorial, 2012.

SILVA, E. T. Unidades de leitura: trilogia pedagógica. Campinas: Autores Associados, 2003.

SFORNI, M. S. de F. Interação entre Didática e Teoria Histórico-Cultural. Educação \& Realidade, Porto Alegre: 40(2), 375-397, 2015.

TANZI NETO, A; THADEI, J; SILVA-COSTA, L. P. da; FERNANDES, M. A.; BORGES, R. R.; MELO, R. Multiletramentos em ambientes educacionais. In. ROJO, Roxane (Org.) Escol@ conectada: os multiletramentos e as TICs. Editora Parábola, São Paulo: 2016.

VYGOTSKY, L. S. La prehistoria del desarollo del lenguaje escrito. In: VYGOTSKY, L. S. Obras Escogidas III: Historia del desarollo de las funciones psíquicas superiores (1931). Madrid: Editora A. Machado Libros, 2006. p. 127-144. 